\title{
Synthesis and electrochemical analysis of Pt-loaded, polypyrrole- decorated, graphene-composite electrodes
}

\author{
Jiyoung Park and Seok Kim* \\ Department of Chemical and Biochemical Engineering, Pusan National University, Busan 609-735, Korea
}

\begin{abstract}
Article Info
Received 5 December 2012

Accepted 4 February 2013

*Corresponding Author

E-mail: seokkim@pusan.ac.kr

Tel: $+82-51-510-3874$

\section{Open Access}

DOI: http://dx.doi.org/

10.5714/CL.2013.14.2.117

This is an Open Access article distributed under the terms of the Creative Commons Attribution Non-Commercial License (http://creativecommons.org/licenses/ by-nc/3.0/) which permits unrestricted non-commercial use, distribution, and reproduction in any medium, provided the original work is properly cited.
\end{abstract}

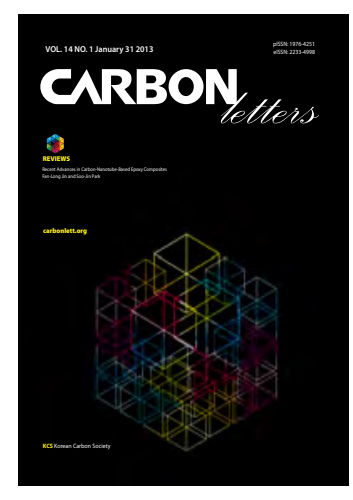

http://carbonlett.org

pISSN: 1976-4251

elSSN: 2233-4998

Copyright $\odot$ Korean Carbon Society

\begin{abstract}
In this study, an electro-catalyst of Pt nanoparticles supported by polypyrrole-functionalized graphene (Pt/PPy-reduced graphene oxide [RGO]) is reported. The Pt nanoparticles are deposited on the PPy-RGO composite by chemical reduction of $\mathrm{H} 2 \mathrm{PtCl} 6$ using NaBH4. The presence of graphene (RGO) caused higher activity. This might have been due to increased electro-chemically accessible surface areas, increased electronic conductivity, and easier charge-transfer at polymer-electrolyte interfaces, allowing higher dispersion and utilization of the deposited Pt nano-particles. Microstructure, morphology and crystallinity of the synthesized materials were investigated using X-ray diffraction and transmission electron microscopy. The results showed successful deposition of Pt nano-particles, with crystallite size of about $2.7 \mathrm{~nm}$, on the PPy-RGO support film. Catalytic activity for methanol electrooxidation in fuel cells was investigated using cyclic voltammetry. The fundamental electrochemical test results indicated that the electro-catalytic activity, for methanol oxidation, of the Pt/PPy-RGO combination was much better than for commercial catalyst.
\end{abstract}

Key words: Pt/PPy, graphene, direct methanol fuel cell

\section{Introduction}

The direct methanol fuel cell (DMFC) is an extremely promising power source for portable applications due to its simple handling and processing of fuel. DMFCs have several advantages (e.g., high energy-conversion efficiency, simple design, and environmental friendliness) compared with hydrogen, for applications involving transportation and portable electronic systems. Such fuel cells can provide a clean power source with high theoretical energy density and low cost, without requiring a separate hydrogen generation system [1]. Despite many efforts devoted to development of the DMFC, there still remain difficulties to be overcome in terms of efficiency and power density. Commercialization of these fuel cells has been facing serious difficulty due to kinetic constraints on the methanol oxidation reaction. To this end, Pt-based electro-catalysts for the methanol electro-oxidation reaction in acid solution has been widely studied in recent years, but high cost and limited quantities have prevented Pt from being used at commercial levels [2]. In addition, the Pt electrocatalyst is poisoned by intermediate products of methanol oxidation (e.g., $\mathrm{CO}_{\mathrm{ads}}$ ). Since the mid-1970s, modification of the catalyst surface has been made by the addition of a second, less expensive metal to the platinum to selectively direct methanol electro-oxidation to the platinum particles [3]. The electro-catalytic activity of Pt-based catalysts can be substantially enhanced by incorporation of other metals or oxides to form binary-alloy catalysts (i.e., $\mathrm{PtRu}, \mathrm{PtSn}, \mathrm{PtFe}$, and PtCo) [4-6]. Conductive polymers, with highly accessible surface areas and high stability, have also been used to improve the activity of the graphene support layer and to enhance dispersal of the metal [7]. With this in mind, we developed a facile and efficient way to deposit Pt nano-particles using polypyrrole, on reduced graphene oxide (RGO) functionalized with conducting polymer. All the results demonstrated that, with 
high electronic conductivity and easier charge transfer, this $\mathrm{Pt} /$ PPy-RGO combination exhibited the higher activity and stability than widely used commercial catalysts.

\section{Experimental}

Graphite oxide was synthesized from natural graphite (SP-1, Bay carbon) by a modification of Hummer's method [8]. The graphite powder was added to a mixture of sulfuric acid, sodium nitrate, potassium permanganate for the acid treatment. The oxidized and treated solution was filtered and washed with $\mathrm{HCl}$ $(10 \%)$; then subjected to centrifugation (3600 rpm, $5 \mathrm{~min})$ to remove residual graphite. The product of synthesis of PPy-RGO composites from $35 \mathrm{mg}$ of graphene and $20 \mathrm{mg}$ of pyrrole, was homogenously dispersed in ethanol-water solution (1:1), then excess $\left(\mathrm{NH}_{4}\right)_{2} \mathrm{~S}_{2} \mathrm{O}_{8}$ was slowly added to the suspension, which was stirred continuously at $0-5^{\circ} \mathrm{C}$ for $8 \mathrm{~h}$. Finally, the resulting PPy-graphene powder was filtered and rinsed, first with water; then with ethanol, until the filtrate was colorless. The black powder so obtained was freeze-dried overnight. The product of synthesis of the Pt/PPy-RGO composites, using Pt/PPy-RGO at 20 $\mathrm{wt} \% \mathrm{Pt}$ loading, was then used as seeds. The PPy-functionalized RGO $(0.1 \mathrm{~g})$ was mixed ultrasonically with $\mathrm{H}_{2} \mathrm{PtCl}_{6} \cdot 6 \mathrm{H}_{2} \mathrm{O}$ in ethylene glycol, after which the $\mathrm{pH}$ was adjusted to $10-11$ by adding $\mathrm{NaOH}(1.0 \mathrm{M})$. The solution was subjected to ultrasonication for $10 \mathrm{~min}$, and N2 bubbling for $20 \mathrm{~min}$; then stirred for 4 $\mathrm{h}$ at $120^{\circ} \mathrm{C}$. After reaction, the resulting solid, black product was isolated by centrifugation, washed with distilled water and ethanol to remove any remaining ions in the final products, and then freeze-dried overnight. This final product is called PPy-RGO supported, Pt nano-particles.

\section{Results and Discussion}

The morphology of the Pt/PPy-RGO product and the deposition of the Pt nano-particles were characterized by transmission electron microscopy (TEM). In Fig. 1a, sheet-like graphene with crimple can be observed. In Fig. 1b, these PPy-assisted, graphene nano-sheets were exfoliated from graphite, and exhibited a smooth, paper-like structure. TEM images of Pt/RGO and Pt/ PPy-RGO are shown in Figs. 1c and d, respectively. In Fig. 1c, the $\mathrm{Pt} / \mathrm{GO}$ combination is shown condensed with other platinum nano-particles, which caused an increase in particle diameters and subsequent decrease in the activity at the Pt nano-particle sites, compared with those of the Pt/PPy-RGO combination.

The X-ray diffraction (XRD) patterns of the Pt/RGO (a) and Pt/PPy-RGO (b) in Fig. 2 revealed distinguishing diffraction peaks. The graphite showed (002) a diffraction peak at $2 \theta=$ $26.5^{\circ}$ [9], but for Pt/PPy-RGO, the diffraction peaks of C (002) plane-shifted negatively. These peaks appeared at $24.8^{\circ}$ and $24.1^{\circ}$, corresponding to an interlayer space of $0.337 \mathrm{~nm}$, and implied successful preparation of the PPy-RGO. The diffraction peaks at $2 \theta=40.2^{\circ}, 46.4^{\circ}$ and $68.2^{\circ}$ could be attributed to the (111), (200) and (220) crystalline planes of the face-centered cubic structure, respectively, of the Pt [10]. The Pt (220) peaks can be used to calculate the average Pt particle size according to the Scherrer equation [11]:

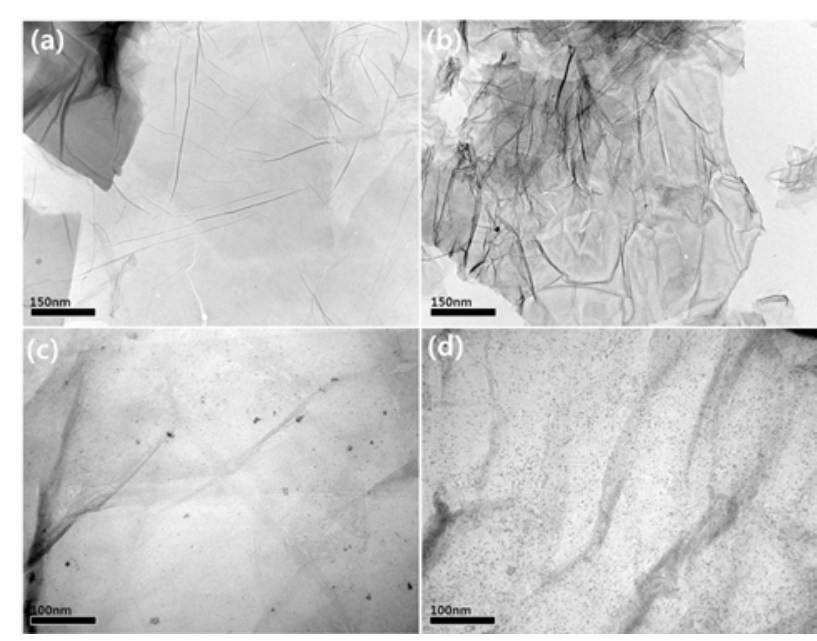

Fig. 1. Transmission electron microscopy images of (a) graphene, (b) PPy-graphene, (c) Pt/RGO and (d) Pt/PPy-RGO. RGO: reduced graphene oxide.

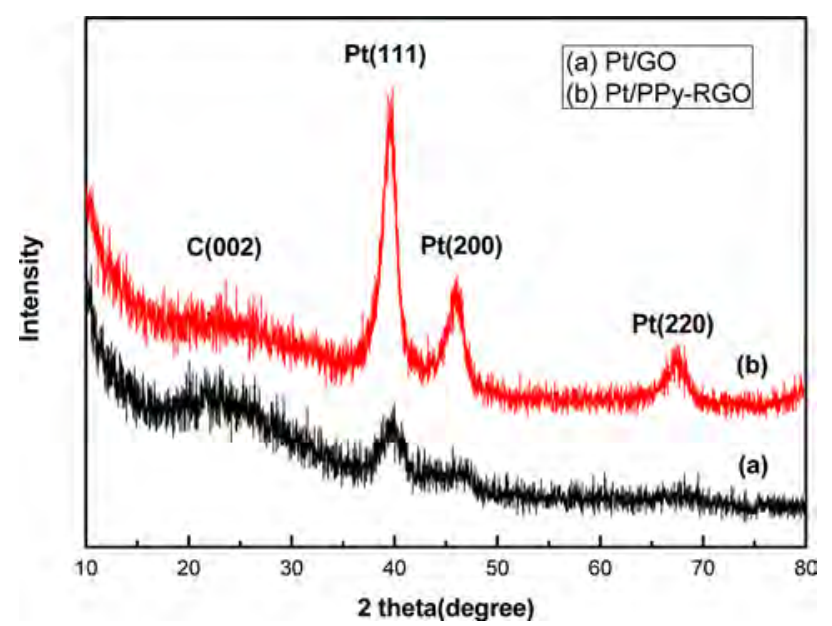

Fig. 2. X-ray diffraction patterns of (a) Pt/RGO and (b) Pt/PPy-RGO. RGO: reduced graphene oxide.

$$
\mathrm{d}=\frac{0.9 \lambda}{\mathrm{B}_{2 \theta} \cos \theta_{\max }}
$$

Where $\mathrm{d}$ is the average particle size (nm), $\lambda$ is the wavelength of the X-ray used $(0.15406 \mathrm{~nm}), B_{2 \theta}$ is the width of the diffraction peak at half height in radians, and $\theta_{\max }$ is the angle at the position of the peak maximum. The calculated mean sizes of $\mathrm{Pt}$ particles were found to be 2.7 and $2.4 \mathrm{~nm}$ for the $\mathrm{Pt} / \mathrm{RGO}$ and $\mathrm{Pt} /$ PPy-RGO electro-catalysts, respectively.

Fig. 3 shows the $\mathrm{CV}$ of $\mathrm{Pt} / \mathrm{RGO}$ and Pt/PPy-RGO in $0.5 \mathrm{M}$ $\mathrm{H}_{2} \mathrm{SO}_{4}$ solution at $20 \mathrm{mV} / \mathrm{S}$ in a potential window of -0.2 to $1.0 \mathrm{~V}$ vs. SCE. Well-defined hydrogen desorption and adsorption peaks in the potential range of -0.05 to $+0.3 \mathrm{~V}$, and irreversible pre-oxidation and reduction peaks in the potential range of +0.5 to $+1.0 \mathrm{~V}$ were observed. The electrochemically active surface area (EAS) was determined by assuming that a monolayer of adsorbed hydrogen requires $210 \mu \mathrm{C} / \mathrm{cm}^{2}$ for its oxidation [12]. The EAS was then calculated using the following equation [13]. 


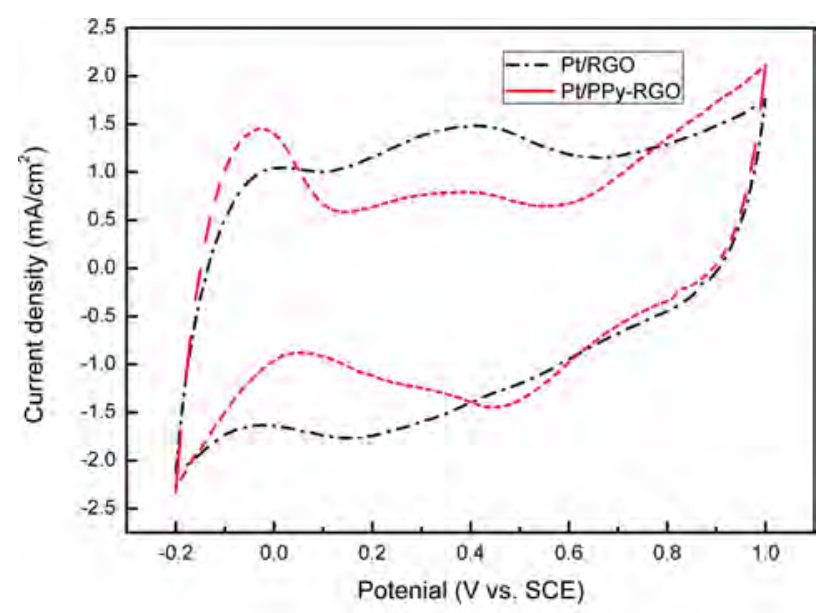

(a)

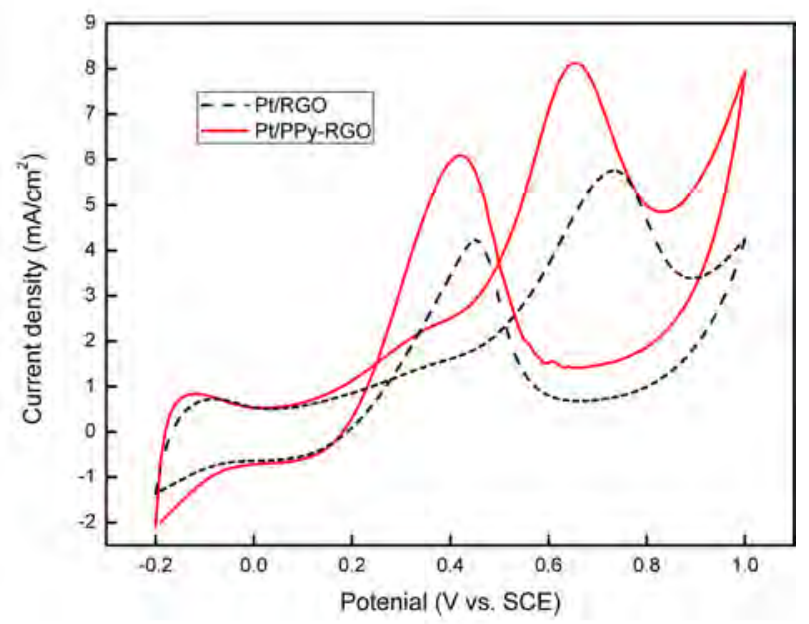

(b)

Fig. 3. (a) Cyclic voltammetry (CV) of $\mathrm{Pt} / \mathrm{RGO}$ and $\mathrm{Pt} / \mathrm{PPy}-\mathrm{RGO}$ in $0.5 \mathrm{M}$ $\mathrm{H}_{2} \mathrm{SO}_{4}$ solution at a scan rate of $50 \mathrm{mVs} 01$ [<<verify unit] between -0.2 and 1.0 V vs. SCE, (b) CV of Pt/RGO and Pt/PPy-RGO in $0.5 \mathrm{M} \mathrm{H}_{2} \mathrm{SO}_{4}$ and $1 \mathrm{M} \mathrm{CH} 3 \mathrm{OH}$ solutions, respectively, at a scan rate of $50 \mathrm{mVs}-1$ between $-0.2 \mathrm{~V}$ and $1.0 \mathrm{~V}$ vs. RGO: reduced graphene oxide, SCE: saturated calomel electrode.

$$
\mathrm{EAS}=\mathrm{Q} / \mathrm{S} 1
$$

Where ' $\mathrm{S}$ ' is the proportionality constant used to relate charge with area and ' $l$ ' is the catalyst loading in ' $g$.' The EAS evaluated from the hydrogen adsorption and desorption peaks was calculated to be 61 and $35 \mathrm{~m}^{2} / \mathrm{g}$ for the Pt/EDTA-GO and Pt/GO catalysts, respectively. The higher EAS of Pt/PPy-RGO was most likely due to the smaller size, and much better dispersion, of the $\mathrm{Pt}$ nano-particles on the polypyrrole-functionalized graphene. Fig. 4 shows the cyclic voltammetry (CV) for methanol electro-oxidation, performed in a solution of $0.5 \mathrm{M} \mathrm{H}_{2} \mathrm{SO}_{4}$ and $1 \mathrm{M}$ $\mathrm{CH} 3 \mathrm{OH}$ at room temperature. It is well known that the ratio of the forward anodic peak current $\left(\mathrm{I}_{\mathrm{f}}\right)$ to the backward anodic peak current $\left(\mathrm{I}_{\mathrm{b}}\right), \mathrm{I}_{\mathrm{f}} / \mathrm{I}_{\mathrm{b}}$, is an index of the tolerance of the catalyst to the poisonous species accumulated on the surface of an electrode [14]. The higher $I_{f} / I_{b}$ ratio indicates that much more methanol is oxidized as carbon dioxide and that intermediate species on the $\mathrm{Pt}$ particles are relatively less. Table 1 shows the values of If and
Table 1. The cyclic voltammetry results for $\mathrm{Pt} / \mathrm{RGO}$ synthesized by different mechanisms

\begin{tabular}{ccccc} 
Sample & $\begin{array}{c}\text { ESA } \\
\left(\mathrm{m}^{2} / \mathrm{g}\right)\end{array}$ & $\begin{array}{c}\mathrm{I}_{\mathrm{f}} \\
\left(\mathrm{mA} / \mathrm{cm}^{2}\right)\end{array}$ & $\begin{array}{c}\mathrm{I}_{\mathrm{b}} \\
\left(\mathrm{mA} / \mathrm{cm}^{2}\right)\end{array}$ & $\mathrm{I}_{\mathrm{f}} / \mathrm{I}_{\mathrm{b}}$ ratio \\
\hline $\mathrm{Pt} / \mathrm{RGO}$ & 35 & 4.0 & 5.7 & 0.7017 \\
\hline $\mathrm{Pt} / \mathrm{PPy}-\mathrm{RGO}$ & 61 & 6.0 & 8.1 & 0.7407 \\
\hline
\end{tabular}

EAS: electrochemically active surface area, RGO: reduced graphene oxide, $\mathrm{l}_{\mathrm{f}}$ : the forward anodic peak current, $\mathrm{l}_{\mathrm{b}}$ : the backward anodic peak current.

Ib. The higher anodic current of Pt/PPy-RGO indicated that the electric conductivity of graphene was higher than the commercial carbon, a result consistent with previous reports [15]. All of the above data reveal that the Pt/PPy-RGO combination exhibits enhanced catalytic activity for methanol oxidation.

\section{Conclusions}

In summary, a convenient and green approach was used to synthesize Pt nano-particles on polypyrrole-assisted graphene for methanol oxidation. XRD and TEM were used to characterize the morphology and structure of the catalysts. The electrocatalytic activities were measured by CV. In comparison with graphene as the support for the catalyst, the polypyrrole-assisted graphene can effectively enhance the electro-catalytic activity of the Pt nanoparticles for the oxidation of methanol. This was due to an increase in the conductivity of the graphene, by the insertion of polypyrrole. All the results indicated that the Pt/ PPy-RGO combination is the more promising catalyst for fuel cell applications.

\section{Acknowledgments}

This work was supported by a 2-Year Research Grant of Pusan National University.

\section{References}

[1] Ren X, Zelenay P, Thomas S, Davey J, Gottesfeld S. Recent advances in direct methanol fuel cells at Los Alamos National Laboratory. J Power Sources, 86, 111 (2000). http://dx.doi.org/10.1016/ S0378-7753(99)00407-3

[2] Heli H, Jafarian M, Mahjani MG, Gobal F. Electro-oxidation of methanol on copper in alkaline solution. Electrochim Acta, 49, 4999 (2004). http://dx.doi.org/10.1016/j.electacta.2004.06.015.

[3] Hamnett A, Kennedy BJ, Weeks SA. Base metal oxides as promotors for the electrochemical oxidation of methanol. J Electroanal Chem, 240, 349 (1988). http://dx.doi.org/10.1016/00220728(88)80337-1.

[4] Kim S, Sohn HJ, Park SJ. Preparation and characterization of carbon-related materials supports for catalysts of direct methanol fuel cells. Curr Appl Phys, 10, 1142 (2010). http://dx.doi.org/10.1016/j. cap.2010.01.016.

[5] Mastragostino M, Missiroli A, Soavi F. Carbon supports for elec- 
trodeposited Pt-Ru catalysts for DMFCs. J Electrochem Soc, 151, A1919 (2004). http://dx.doi.org/10.1149/1.1805751.

[6] Antolini E, Salgado JRC, Giz MJ, Gonzalez ER. Effects of geometric and electronic factors on ORR activity of carbon supported Pt-Co electrocatalysts in PEM fuel cells. Int J Hydrogen Energy, 30, 1213 (2005). http://dx.doi.org/10.1016/j.ijhydene.2005.05.001.

[7] Zhao H, Li L, Yang J, Zhang Y. Co@Pt-Ru core-shell nanoparticles supported on multiwalled carbon nanotube for methanol oxidation. Electrochem Commun, 10, 1527 (2008). http://dx.doi. org/10.1016/j.elecom.2008.07.047

[8] Hummers WS, Offeman RE. Preparation of graphitic oxide. J Am Chem Soc, 80, 1339 (1958). http://dx.doi.org/10.1021/ ja01539a017.

[9] Mirabile Gattia D, Antisari MV, Giorgi L, Marazzi R, Piscopiello E, Montone A, Bellitto S, Licoccia S, Traversa E. Study of different nanostructured carbon supports for fuel cell catalysts. J Power Sources, 194, 243 (2009). http://dx.doi.org/10.1016/j.jpowsour.2009.04.058.

[10] Si Y, Samulski ET. Exfoliated graphene separated by platinum nanoparticles. Chem Mater, 20, 6792 (2008). http://dx.doi org $/ 10.1021 / \mathrm{cm} 801356 \mathrm{a}$

[11] Zhao Y, Yang X, Tian J, Wang F, Zhan L. Methanol electro-oxida- tion on Ni@Pd core-shell nanoparticles supported on multi-walled carbon nanotubes in alkaline media. Int J Hydrogen Energy, 35, 3249 (2010). http://dx.doi.org/10.1016/j.ijhydene.2010.01.112.

[12] Venkateswara Rao C, Viswanathan B. ORR Activity and direct ethanol fuel cell performance of carbon-supported $\mathrm{Pt}-\mathrm{M}(\mathrm{M}=\mathrm{Fe}$, $\mathrm{Co}$, and $\mathrm{Cr}$ ) alloys prepared by polyol reduction method. J Phys Chem C, 113, 18907 (2009). http://dx.doi.org/10.1021/jp9041606.

[13] Li W, Zhou W, Li H, Zhou Z, Zhou B, Sun G, Xin Q. Nanostuctured $\mathrm{Pt}-\mathrm{Fe} / \mathrm{C}$ as cathode catalyst in direct methanol fuel cell. Electrochim Acta, 49, 1045 (2004). http://dx.doi.org/10.1016/j. electacta.2003.10.015.

[14] Wang L, Guo S, Zhai J, Dong S. Facile Synthesis of Platinum Nanoelectrocatalyst with Urchinlike Morphology. J Phys Chem C, 112, 13372 (2008). http://dx.doi.org/10.1021/jp804484f.

[15] Lee SY, Park SJ. Comprehensive review on synthesis and adsorption behaviors of graphene-based materials, Carbon Lett, 13, 73 (2012). http://dx.doi.org/10.5714/CL.2012.13.2.073. 